\title{
TÜRK SPORCUSUNUN SPORDAN BEKLENTILERI ILE SPORA YÖNELTEN UNSURLAR*
}

\author{
Hakan SUNAY ${ }^{1}$
}

A. Seda SARACALOĞLU²

\section{ÖZET}

Bu çalışmanın amacı, Türkiye'de futbol branşı dışındaki spor branşlarında yarışan sporcuların sayılarındaki azalmaya neden olan etkenleri belirlemektedir. Araştırmanın amacını gerçekleştirmek üzere elde edilen veriler anket yoluyla elde edilmiştir. Araştırmada kullanılan anket formu önce benzer araştırma örneklerinden yararlanılarak taslak form haline getirilmiş, daha sonra uzman beden eğitimi öğretmeni, antrenör ve sporcuların görüşleri alınarak anket formuna son şekli verilmiştir. Anketten elde edilen verilere dayalı olarak anketin \& iç tutarlılık güvenilirlik katsayısı .8434 olarak hesaplanmıştır. Araştırma 1996 yılında gerçekleştirilmiştir. Araştırmaya Ankara, İzmir ve Manisa illerinde lisansı ılarak spor yapan 15 spor branşından 451 sporcu katılmıştır. Anketten elde edilen veriler, frekans ve yüzdelerle açıklanmış ve yorumlanmıştır. Ayrıca araştırmaya katılan sporcuların yaptıkları spor branşlarına, cinsiyetlerine, spor yapma yıllarına ve aylık gelir durumlarına göre görüşler arasındaki farkın önemli olup olmadığını tespit etmek amacıyla, tek yönlü varyans analizi yapılmış, farkın önemli olduğu durumlarda ise çoklu karşılaştırma tekniklerinden Fischer'in en küçük önemli farklar testi kullanılmıştır. İstatistiksel anlamlıık için ise .05 anlamlııı düzeyi seçilmiştir.

Araştırmanın sonunda, Türkiye'de futbol dışındaki branşlarda lisansı olarak spor yapan sporcuları öncelikle ailesi, yakın çevresindeki ilgili antrenör ve arkadaş grubunun spora yönlendirmedeki etkisinin yüksek, televizyon ve basın yayın organları gibi kitle iletişim araçlarının ise spora yönlendirmedeki etkisinin oldukça az düzeyde olduğu belirlenmiştir.

Ayrıca Türkiye'de Lisanslı spor yapan sporcuların yaptıkları spor branşıyla ilgili, sağlıklı olmak, iyi bir fiziki görünüme sahip olmak ve milli takıma seçilmek gibi bazı beklentilerinin olduğu belirlenmiştir. Öte yandan sporcuların yaptıkları spor branşına teşvik eden unsurlara, spor branşıyla uğraşma nedenlerine, spor yaparak olmasını bekledikleri beklentilere ve uğraşılan spor branşında sportif başarıyı ve performansı olumlu yönde etkileyebilecek faktörlere ilişkin görüşleri arasındaki farkın, spor branşlarına, spor yapma yıllarına, ve aylık gelirlerine göre önemli olduğu belirlenirken, cinsiyet değişkenine göre ise önemli bulunmamıştır.

Anahtar Kelimeler: Lisanslı sporcu, spora yönelten unsurlar, spordan beklentiler

\section{THE FACTORS DIRECT TO THE BRANCHES OF TURKISH ATHLETES AND THEIR EXPECTATIONS}

\section{ABSTRACT}

The purpose of this study is to determine the factors that cause the decrease in the number of athletics in al sport branches, expect football, in Turkey. The data of this study has been gained by means of questionnaire. The questionnaire form of the study was put into a rough draft with the help of similar. Studies of this own first and then was put into its exact shape by having the ideas of experts, physical education teachers, trainers and athletes. According to the data of the questionarire, the coherent reliability coefficient of the questionarie was calculated as .8434 the study was carried out in 1996. 451 licensed athletes from Ankara, İzmir and Manisa from 15 different branches included in the study. The data gained in the questionnaire was explaineded and interpretted by frequency and percentages. And in order to determine if there's a major difference between the ideas according to the sport branches, sexes sport ages and salaries of the athletes that included in the study on way variaance analysis was carried out, and when there's a major difference, one of the multiple comparison tecniques Fisher's minimum major differences test was used. And as for the statistical meaningfulness, .05 meaningfulness level was chosen.

As a result of the research, it was determined that families trainer in the close environment and the friends of the licenced athletes in all sport branches of Turkey, expect football have on high; and mass communication means such as television press publishing organs have a low influence in directing athletes to the sport it was also determined that the lincenced athletes in Turkey had some expectations related to their sport branches, such as being healty, having a good physical appearance and being chosen to the National Team.

On the other hand, the differences between the factors that encourage the athletes to their sport branches, reasons for dealing with their sport branches, expectation from their sport branches according to the ideas of experts related to the performances of the athletes are relevant to their sport branches, sport ages and montly incomes but not sexes.

This study was presented on 4-6 December 1977 that was organized in Singapore by AIESEP.

Key Words: Licenced athletes, factors directing to branches, expectation from sport.

\section{GíRiş VE AMAÇ}

Spor, bireylerin fiziksel, zihinsel, duygusal ve sosyal yönden gelişimlerini sağlayan, bilgi, beceri ve liderlik yeteneklerini geliştiren bir araçtır. Spor, insanın kendi kendisini disipline etmesine karşılaşacağı psikolojik ve fizyolojik sorunların üstesinden gelmesine yardım eder. Sporun uluslararası dostluk ve barış ile ülke ekonomisine getirdiği olumlu

\footnotetext{
Bu çalışma, 4-6 Aralık 1997 tarihleri arasında Singapur'da AIESEP tarafından organize edilen Uluslararası Spor Bilimleri Kongresinde Poster Bildiri olarak sunulmuştur.

1 Ankara Üniversitesi Beden Eğitimi ve Spor Yüksekokulu

2 Adnan Menderes Üniversitesi Eğitim Fakültesi
} 
katkılarda vardır. Ayrıca, günümüzde gerek basın yayın organlarının spora yaklaşımı, gerekse insanların stresten kurtulma, vücutlarını formda tutma çabaları ve hepsinin ötesinde sporda kazanılan uluslararası başarılar, toplumun günlük yaşamında ve moral düzeyinde oldukça önemli hale gelmiş, spora önemli bir boyutta kazandırmıştır (1, 2). Nitekim günümüzde spor yapmak sportif aktivite içinde bulunmak, uygar insan olmanın da koşulları arasında yer almıştır (3). Bu noktada, devletinde spor olgusunu güçlendirmesi, yaygınlaştırması ve bununla ilgili tedbirleri alması oldukça önemli hale gelmiştir. Bu bağlamda devletin spor aktiviteleri geliştirmesi, yaygınlaştırması beklenilen bir durumdur. Kuralları ve yarışma biçimleri birbirinden farklı oyunların organizasyonlarıyla gerçekleşen sportif aktivitelerin toplumda yaygınlaştırılarak yapılır ve uygulanır hale gelmesi oldukça önemlidir. Bu çerçevede, Türkiye 'de olimpik ve henüz olimpik olmayan toplam 37 spor branşı, federasyon örgütlenmesini tamamlayarak etkinliklerini sürdürmektedir. Gençlik ve Spor Genel Müdürlüğü'ne bağlı olarak etkinliklerini sürdüren futbol branşı hariç, söz konusu 37 federasyonun bir çok uluslararası başarıları da bulunmaktadır ( 4 ).

Ancak ne var ki, Türkiye'de futbol branşı dışındaki spor branşlarının 1995-1996 yılı itibariyle 119600 olan lisanslı sporcu sayısı, 1996 yılı itibariyle 106764 ' e düşmüştür ( 5,6 ). Sporcu sayısındaki bu düşme, Türk sporunun gelişimini olumsuz yönde etkileyebilecektir. Bu nedenle futbol branşı dışındaki spor branşlarında lisanslı spor yapan sporcu sayısındaki düşme nedenlerinin belirlenmesine yönelik inceleme önemli görülmektedir. Bu araştırmanın amacı da, Türkiye'de futbol branşı dışındaki spor branşlarında yarışan sporcuların sayılarındaki azalmaya neden olan etkenleri belirlemektir. Buna göre araştırmada şu sorulara yanıt aranmıştır;

1- Sporcuların, yaptıkları spor branşına teşvik eden unsurlara ilişkin görüşleri nedir? Bu görüşler, cinsiyet, spor branşlarına, spor yapma yılına ve aylık gelire göre değişmekte midir?

2- Sporcuların, spor branşıyla uğraşma nedenlerine ilişkin görüşleri nedir? Bu görüşler, cinsiyete, Spor branşlarına, spor yapma yılına ve aylık gelire göre değişmekte midir?

3- Sporcuların, spor yaparak olmasını bekledikleri beklentilere ilişkin görüşleri nedir? Bu görüşle, cinsiyete, Spor branşlarına, spor yapma yılına ve aylık gelire göre değişmekte midir?

4- Sporcuların, uğraşılan spor branşında sportif başarıyı ve performansı olumlu yönde etkileyebilecek faktörlere ilişkin görüşleri nedir? Bu görüşler, cinsiyete, Spor branşlarına, spor yapma yılına ve aylık gelire göre değişmekte midir?

\section{MATERYAL VE YÖNTEM}

\section{Materyal ( Çalışma Grubu ) ; Araştırmanın çalışma evreni, 31.12.1996 Gençlik ve Spor Genel Müdürlüğü}

(GSGM ) sicil ve lisans müdürlüğü verilerine göre Türkiye'de lisanslı olarak spor yapan bayan ve erkek 106774 sporcudur. Ancak, araştırmada bu evrenden bir örneklem alma yoluna gidilmemiştir. Araştırmaya ilişkin veriler, Ankara, İzmir ve Manisa illerinde lisanslı olarak spor yapan ( futbol hariç ) farklı spor branşlarından kesit alma yaklaşımıyla elde edilmiştir. Araştırma, 1996 yılında gerçekleştirilmiştir. Araştırmaya, Ankara, İzmir ve Manisa illerinde lisanslı olarak spor yapan $15\left(^{*}\right)$ spor branşından 451 sporcu katılmıştır. Söz konusu spor branşları değerlendirmelerde dört $\left({ }^{* *}\right)$ kategoride toplanmıştır.

Yöntem ; Araştırmanın amacını gerçekleştirmek üzere elde edilen veriler, yalnızca lisanslı olarak spor yapanlardan elde edilmiştir. Araştırmada sporculara anket uygulanmıştır. Araştırmada kullanılan anket formu, önce benzer araştırma örneklerinden yararlanılarak taslak form haline getirilmiş, daha sonra uzman, beden eğitimi öğretmeni, antrenör ve sporcuların görüşleri alınarak anket formuna son şekli verilmiştir. Anketten elde edilen verilere dayalı olarak, anketin $\propto$ iç tutarlılık güvenilirlik katsayısı .8434 olarak hesaplanmıştır. Buna göre, araştırmada uygulanan aracın güvenilir bir araç olduğundan söz edilebilir. Anketten elde edilen veriler, frekans ve yüzdelerle açıklanmış ve yorumlanmıştır. Ayrıca araştırmaya katılan sporcuların yaptıkları spor branşlarına, cinsiyetlerine, spor yapma yıllarına ve aylık gelir durumlarına göre görüşler arasında önemli fark olup olmadığını tespit etmek amacıyla tek yönlü varyans analizi yapılmış, farkın önemli olduğu durumlarda ise çoklu karşılaştırma tekniklerinden Fisher'in en küçük önemli farklar testi kullanılmıştır.

İstatistiksel anlamlılık için ise .05 anlamlılık düzeyi seçilmiştir.

\section{BULGULAR VE YORUMLAR}

Araştırmadan elde edilen veriler araştırmanın amacı doğrultusunda beş boyutta gruplandırımıştır ;

1- Kişisel Bilgilere İlişkin Bulgular ; Araştırmaya 157 bayan, 294 erkek toplam 451 sporcu katılmıştır. Bu sporcular futbol hariç $15^{(*)}$ değişik spor branşında, 249 A takım ve 202 genç takım düzeyinde spor yapmaktadır. Sporcuların aylık gelir düzeylerine bakıldığında \%1.11'inin ayda 10-15 milyon , \%2.22'sinin 16-21 milyon, \% 6.43'ünün 22-27 milyon, \%13.75'inin 28-33 milyon, \%27.94'ünün 34-39 milyon, \%35'nin 50-60 milyon ve \% 13.53 'ünün 70 milyonun üzerinde gelirleri olduğu tespit edilmiştir. Sporcuların, spor yapma yıllarına bakıldığında \% 36.59 oranında 0-4 yıl, \% 54.55 oranında 4-9 yıl, \%7.32 oranında 10-14 yıl ve \% 1.55 oranında 15 yıl ve üzeri süredir spor yaptıkları bulunmuştur. Dört $\left.^{* *}\right)$ değişik spor branşının dağılımı \%38.14 oranında takım sporları, \%32.15 oranında bireysel sporlar, \%17.74 oranında mücadele sporları ve \%11.97 oranında raket sporları şeklindedir.

\footnotetext{
Voleybol, basketbol, hentbol, kürek, karate, taekwondo, güreş, masa tenisi, tenis, halter, cimnastik, yüzme, sportif ritmik cimnastik, atletizm, eskrim

Takım sporları, bireysel sporlar, mücadele sporları, raket sporları
} 


\section{2- Sporcuların Yaptıkları Spor Branşına İlişkin Görüşleri ;}

Sporcuların yaptıkları spor branşına ilişkin görüşleri tablo1 ' de görülmektedir.

Tablo 1- İlgili Spor Branşına Teşvik Eden Unsurlara İlişkin Görüşlerin Sıralaması

\begin{tabular}{||c|l|c|c||}
\hline \hline Madde No: & Spor Branşına Teşvik Eden Unsurlar & X & Önem Sırası \\
\hline a & Anne baba ve kardeşin, spora yönlenmedeki etkisi & 3.14 & 1 \\
\hline h & Yakın çevredeki ilgili spor branşı antrenörünün spora yönlenmedeki etkisi & 3.11 & 2 \\
\hline c & Arkadaş ve akran grubunun, spora yönlenmedeki etkisi & 2.97 & 3 \\
\hline d & Beden Eğitimi öğretmeninin, spora yönlenmedeki etkisi & 2.64 & 4 \\
\hline b & Çevre koşullarının ( mahalle gibi ) spora yönlenmedeki etkisi & 2.58 & 5 \\
\hline g & Okul spor salonu ve tesislerinin spora yönlenmedeki etkisi & 1.99 & 6 \\
\hline f & Televizyon kanallarının spora yönlenmedeki etkisi & 1.98 & 7 \\
\hline e & Basın-Yayın organlarının spora yönlenmedeki etkisi & 1.88 & 8 \\
\hline
\end{tabular}

Tablo 1'de görüldüğü gibi lisanslı olarak spor yapan sporcuları spora teşvik eden unsurların başında, anne, baba, kardeş ve yakın çevredeki ilgili spor branşı antrenörünü gelmektedir. Televizyon kanalları ve basın yayın organları ise spora teşvik eden unsurların sonunda yer almaktadır. Bu durum ülkemizde futbol dışındaki spor branşlarında spor yapan insanların, spora ailesinin ve yakın çevresinin teşviki ile başladığını, televizyon ve basın yayın organlarının spora teşvik etmede etkili olmadığını göstermektedir. Oysa, kitle iletişim araçları olarak adlandırılan televizyon ile basın yayın organlarının etkinliği günlük yaşamda oldukça fazladır. Özelliklede 1980'li yıllardan itibaren ülkemizde gazete, dergi, radyo gibi kitle iletişim araçları içerisinde önemi her geçen gün biraz daha artan televizyonun birçok fonksiyonu yanında, insanları aktif spora yönlendirebilecek önemli bir teşvik gücüne sahip olduğu görülmektedir (7). Karaküçük ve arkadaşlarının (1996) yaptığı bir araştırmada Türkiye'de etkin televizyon yayıncılığı yapan altı televizyon kanalının Avrupa'daki televizyon yayınlarına oranla spor programlarına daha az yer ayırdığını, söz konusu spor programlarının ise futbol ağırlıklı olduğu saptanmıştır. Ayrıca aynı araştırmada, devlet televizyonunun spor programları açısından yetersizliği de ortaya konmuştur (8). Böylece Türkiye'de bulunan televizyon ile basın ve yayın kuruluşlarının futbol dışında insanları ekranlardan aktif spora yönlendirecek diğer spor branşlarının tanıtımları konusunda yetersiz kaldıkları düşünülebilir.

İlgili spor branşına teşvik eden unsurlara ilişkin sporcu görüşleri arasındaki farkın cinsiyet ve aylık gelire göre önemli olmadığı belirlenirken, spor branşları arasındaki incelemede, çevre koşulları ile arkadaş grubunun spora yönlendirmedeki etkisine ilişkin olarak mücadele sporları lehinde, beden eğitimi öğretmeninin, basın yayın organlarının ve okul spor tesis ile malzemelerinin spora yönlendirmedeki etkisine ilişkin olarak ise takım sporları lehinde farkın önemli olduğu saptanmıştır ( $p<0.05$ ). Bu durum, orta öğretim kurumlarında uygulanan beden eğitimi dersi öğretim programında voleybol, basketbol, hentbol gibi takım sporlarına etkin olarak yer verildiğinden kaynaklanıyor olabilir.

İlgili spor branşına teşvik eden unsurlara ilişkin sporcu görüşleri arasındaki farkın, spor yapma yılına göre 15-19 yıllar arasında spor yapanlar lehinde önemli olduğu saptanmıştır $(p<0.05)$.

\section{3- Sporcuların İlgili Spor Branşıyla Uğraşma Nedenlerine İlişkin Görüşleri ;}

Sporcuların ilgili spor branşıyla uğraşma nedenleri tablo 2'de görülmektedir.

Tablo 2 - İlgili Spor Branşıyla Uğraşma Nedenlerine İlişsin Görüşlerin Sıralanması

\begin{tabular}{||c|l|c|c||}
\hline \hline Madde No & İlgili Spor Branşıyla Uğraşma Nedenleri & X & Onnem Sırası \\
\hline b & İlgili spor branşını sevmek & 4.33 & 1 \\
\hline h & Başarı kazanmaktan zevk duymak & 4.09 & 2 \\
\hline f & İlgili spor branşıyla uğraşarak sağlıklı olmak & 3.62 & 3 \\
\hline e & Spor yaparak boş zamanlarını olumlu değerlendirmek & 3.61 & 4 \\
\hline c & Sporun olumlu katkılarından haberdar olmak & 3.58 & 5 \\
\hline I & Arkadaşlarla birlikte bir takım ruhu içinde hareket etmek & 3.37 & 6 \\
\hline g & Sporcu olarak arkadaşların arasında tanınıp sevilmek ve sayılmak & 3.01 & 7 \\
\hline d & Kolayca bir arkadaş grubunun üyesi olmak & 2.90 & 8 \\
\hline a & Maddi geliri arttırmak & 1.90 & 9 \\
\hline
\end{tabular}


Tablo 2'de görüldüğü gibi, lisanslı olarak spor yapan sporcuların spor yapma nedeni olarak en önde "ilgili spor branşını sevmek" gelmektedir. Daha sonra sırasıyla "Başarı kazanmaktan zevk duymak" ve "İlgili spor branşıyla uğraşarak sağlıklı olmak" gibi nedenler gelirken, "Maddi geliri arttırmak" nedeni en son sırada yer almıştır. Bu bulgu Türkiye'deki sporcuların sporu maddi gelirlerini arttırmak için değil, sporu sevdikleri ve başarı kazanmaktan zevk duydukları için yaptıklarını göstermektedir.

İlgili spor branşlarıyla uğraşma nedenlerine ilişkin sporcu görüşleri arasındaki fark, cinsiyete göre önemli bulunmamıştır. Ancak aylık gelire göre, "İlgili spor branşını sevmek" ve "Başarı kazanmaktan zevk duymak" gibi nedenler arasındaki fark aylık geliri 16-21 milyon TL olan sporcular lehine önemli bulunmuştur ( $p<0.05)$.

Spor branşları arasındaki incelemede, "Maddi gelir arttırmak" ve "Arkadaşlarla birlikte bir takım ruhu içinde hareket etmek" nedenleri takım sporları lehinde, "Spor branşını sevmek" ve "Boş vakit geçirmek" gibi nedenler arasındaki fark ise, raket sporları lehinde önemli bulunmuştur $(p<0.05)$.

İlgili spor branşıyla uğraşma nedenlerine ilişkin sporcu görüşleri arasındaki fark, spor yapma yılına göre, 15-19 yıllar arasında spor yapanlar lehinde önemli olduğu saptanmıştır $(p<0.05)$. Bu bulgu çerçevesinde, sporcuların spor yapma yaşları yükseldikçe spor yapma nedeni olarak, "Maddi geliri arttırmak", "Kolayca bir arkadaş grubunun üyesi olmak" ve "Sporcu olarak tanınıp sevilmek" önemli nedenler arasında yer almaktadır.

\section{4- Sporcuların Uğraştıkları Spor Branşından Beklentilerine İlişkin Görüşleri ;}

Sporcuların uğraştıkları spor branşından beklentilerine ilişkin görüşleri tablo3' de görülmektedir.

Tablo3 - Sporcuların Uğraştıkları Spor Branşından Beklentilerine İlişkin Görüşlerinin Sıralaması

\begin{tabular}{||c|l|c|c||}
\hline \hline Madde No & Sporcuların Uğraştıkları Spor Branşından Beklentileri & X & Önem Sırası \\
\hline a & Sağlıkı olmak ve sağlığını korumak & 3.91 & 1 \\
\hline i & Milli Takıma seçilmek, milli olmak & 3.64 & 2 \\
\hline b & İyi bir fiziki görünüme sahip olmak & 3.53 & 3 \\
\hline f & Antrenör olmak & 3.41 & 4 \\
\hline e & İlerde sporla ilgili üniversiter düzeyde eğitim görmek & 3.01 & 5 \\
\hline c & Çevresiyle spor yapan popüler bir insan olarak ilişkilerini sürdürmek & 2.92 & 6 \\
\hline d & İyi bir sporcu olmak ve hayatını spor yaparak kazanmak & 2.88 & 7 \\
\hline I & Maddi olanaklara kavuşmak & 2.73 & 8 \\
\hline h & Beden Eğitimi öğretmeni olmak & 2.48 & 9 \\
\hline g & Hakem olmak & 2.31 & 10 \\
\hline \hline
\end{tabular}

Tablo 3'de görüldüğü gibi lisanslı olarak spor yapan sporcuların, önde gelen beklentisi, "Spor yaparak sağlıklı olmak ve sağlığını korumak", "Milli takıma seçilip, milli olmak", "İyi bir fiziki görünüme sahip olmak" ve "Antrenör olmak" olmuştur. Öte yandan sporcuların, "Spor yaparak maddi olanaklara kavuşmak", "Beden Eğitimi öğretmeni olmak" ve "Hakem olmak" beklentileri de son sıralarda yer almıştır. Bu bulgu, sporcuların spor yapma nedenlerine ilişkin görüşleri ile aynı paraleldedir. Sporcular, maddi gelir sağlamak için spor yapmadıkları gibi, yaptıkları spordan maddi bir beklentileri de bulunmamaktadır.

Sporcular öncelikle, spor yaparak sağlıklı olmak isterken, maddi olanaklara kavuşmak, beden eğitimi öğretmeni ve hakem olmak gibi spor yoluyla maddi kazanç elde edecek beklentilerden uzaklaşmışlardır. Sporcular, sporu tamamen amatörce gerçekleştirmek beklentisi içerisindedirler.

Uğraşılan spor branşı ile ilgili beklentilere ilişkin sporcuların görüşleri arasındaki fark, cinsiyete göre önemli bulunmamıştır. Ancak aylık gelire göre, "İyi bir fiziki görünüme sahip olmak", "İyi bir sporcu olmak ve hayatını spor yaparak kazanmak" ve "lileride sporla ilgili üniversiter düzeyde eğitim görmek" gibi beklentiler arasındaki fark, 10-15 milyon TL aylık geliri olan sporcular lehinde önemli bulunmuştur $(p<0.05$ ). Şüphesiz, 10-15 milyon TL aylık geliri olan bir sporcunun önde gelen beklentisi maddi gelirini arttırmak olabilir. Ancak bu gruptaki sporcuların maddi olanaklarını arttırma yanında, sporu sağlıklı olmak, iyi bir fiziki görünüme sahip olmak için yapıyor olması da olumlu bir bulgu olarak değerlendirilebilir.

Spor branşları arasındaki incelemede "Çevresiyle ilişkilerini sürdürmek", "İlerde sporla ilgili üniversiter düzeyde eğitim görmek", "Beden Eğitimi öğretmeni olmak" ve "Milli takıma seçilmek ve milli olmak" gibi beklentilere ilişkin sporcu görüşleri arasındaki fark, bireysel sporlarla uğraşan sporcular lehinde önemlidir $(p<0.05)$. Öte yandan "İyi bir sporcu olarak hayatını kazanmak" beklentisi ile "Maddi olanaklara kavuşmak" beklentisine ilişkin sporcu görüşleri arasındaki fark, takım sporlarıyla uğraşan sporcular lehine önemli bulunmuştur $(p<0.05)$.

Spor yaparak ilerde olması beklenilen beklentiler ile ilgili sporcu görüşleri arasındaki fark, "İyi bir sporcu olmak ve hayatını spor yaparak kazanmak", "İlerde sporla ilgili üniversiter düzeyde eğitim görmek" ve "Maddi olanaklara kavuşmak" beklentileri, spor yapma yılı 10-14 yıl olan sporcular lehinde önemli bulunmuştur $(p<0.05)$. 


\section{Görüşler : \\ 5- İlgili Spor Branşında Sportif Başarıyı ve Performansı Olumlu Yönde Etkileyebilecek Faktörlere İlişkin}

İlgili spor branşında sportif başarıyı ve performansı olumlu yönde etkileyebilecek faktörlere ilişkin sporcu görüşlerin sıralaması tablo4 'de görülmektedir.

Tablo 4- İlgili Spor Branşında Sportif Başarıyı ve Performansı Olumlu Yönde Etkileyebilecek Faktörlere İlişkin Görüşlerin Siralaması

\begin{tabular}{||c|l|c|c||}
\hline \hline Madde No & Davranış & X & Önem Sırası \\
\hline c & Antrenman & 4.55 & 1 \\
\hline a & Beslenme ve diyet & 4.43 & 2 \\
\hline k & Antrenör & 4.39 & 3 \\
\hline I & Sportif yetenek & 4.37 & 4 \\
\hline i & lyi bir antrenman ile sportif beceri kazanmak & 4.33 & 5 \\
\hline n & İi bir kulüp yönetimi & 4.31 & 6 \\
\hline j & Hırs & 4.29 & 7 \\
\hline h & Sosyal güvenlikte olmak & 4.20 & 8 \\
\hline f & Manevi olanakların sağlanması ( kupa, takdir alma vs. ) & 4.12 & 9 \\
\hline e & Düzenli yaşam şekli & 4.06 & 10 \\
\hline I & Tesis & 4.05 & 11 \\
\hline g & Düzgün aile yaşantısı & 3.85 & 12 \\
\hline d & Maddi olanakların sağlanması & 3.85 & 13 \\
\hline m & Takım içi arkadaşlık & 3.72 & 14 \\
\hline b & Doping & 1.57 & 15 \\
\hline \hline
\end{tabular}

Tablo 4'de görüldüğü gibi lisanslı sporcular "antrenman", "beslenme ve diyet", "antrenör" ve "sportif yetenek" gibi sportif başarıyı olumlu yönde etkileyebilecek faktörler birinci sıraya yerleşirken, "maddi olanaklara kavuşmak", "takım içi arkadaşlık" ve "doping" son sırayı paylaşmışlardır.

İlgili spor branşında sportif başarıyı ve performansı olumlu yönde etkileyebilecek faktörlere ilişkin sporcu görüşleri arasındaki farkın, cinsiyete göre önemli olmadığı belirlenirken, aylık gelire göre ise, yüksek aylık alan sporcular lehinde fark önemli bulunmuştur ( $p<0.05$ ).

İlgili spor branşında sportif başarıyı ve performansı olumlu yönde etkileyebilecek sporcu görüşleri arasındaki fark, "maddi olanakların sağlanması", "düzenli yaşam şekli", "düzgün aile yaşantısı", "tesis", "takım içi arkadaşlık" ve "iyi bir kulüp yönetimi" faktörlerine göre takım sporları lehinde önemli bulunmuştur ( $p<0.05$ ).

Öte yandan, sporcuların "sosyal güvenlikte olmak" ve "antrenman" faktörlerine ilişkin görüşleri arasındaki fark önemli bulunmuştur $(p<0.05)$.

İlgili spor branşında sportif başarıyı ve performansı olumlu yönde etkileyebilecek sporcu görüşleri arasındaki fark, spor yapma yılına göre "maddi olanakların sağlanması", "sportif yetenek" ve "tesis" faktörlerine ilişkin spor yapma yılına göre 10-14 yıllar arasında spor yapanlar lehine önemli olduğu saptanmıştır ( $p<0.05)$.

\section{SONUÇ VE ÖNERILER}

Araştırma bulgularına dayalı olarak şu sonuçlara varılmıştır:

1- Türkiye'de futbol dışındaki branşlarda lisanslı olarak spor yapan sporcuları, ailesi (anne, baba ve kardeş ), yakın çevresindeki ilgili antrenör ve arkadaş grubu spora yönlendirmektedir. Ancak televizyon ve basın yayın organları gibi geniş halk kitlelerine ulaşabilen kitle iletişim araçlarının spora yöneltmekteki etkisi son derece az olmaktadır. Buna göre, Türkiye'de televizyon ve basın yayın organlarının spora yöneltmekteki etkisi arttırılmalı futbol dışındaki spor branşlarını da tanıtıcı ve eğitici yayınlar yapılmalıdır.

2- Türkiye'de futbol dışındaki spor branşlarında lisanslı olarak spor yapanlar öncelikle o branşı sevdikleri için yapmaktadırlar. Yani Türkiye'de, futbol dışındaki sporlara yönelme duyuşsal faktörlerin etkisiyle olmaktadır. O halde, aile ve yakın çevrenin etkisiyle spora yönelen Türk toplumunun spora yönelmede esas teşkil eden duyuşsal özelliklerinin arttırılması sağlanmalıdır. Bununla ilgili olarak da Türkiye'de sporla ilgili tüm kamu ve özel spor kurum ve kuruluşlarına büyük görev düşmektedir.

3- Türkiye'de lisanslı spor yapan sporcuların yaptıkları spor branşıyla ilgili beklentileri vardır. Bu beklentilerin başında spor yaparak sağlıklı olmak, iyi bir fiziki görünüme sahip olmak ve milli takıma seçilmek gelmektedir. O halde, toplumda sporun yaygınlaştırılmasına yönelik çalışmalara yer verilmesi, söz konusu beklentilerin gerçekleşmesi açısından oldukça önemlidir. Buna göre, Türkiye'de futbol dışındaki spor branşlarının yaygınlaştırılması için gerekli spor tesisi, spor eğiticisi, araç gereç ve malzeme ile spor organizasyonlarının sık sık gerçekleştirilmesi gereklidir. 
4- Türkiye'de lisanslı olarak spor yapan sporcular, sportif başarıyı ve performansı olumlu yönde etkileyebilecek unsurların başında antrenman, beslenme, antrenör ve sportif yeteneğin geldiğini belirtmişlerdir. O halde sporu, sevdiği için, hiçbir maddi beklentisi olmadan yapan sporcuların bu intiyaçlarının karşılanması gereklidir. Bunun için de yine spor tesislerinin sağlıklı ve verimli kullanılması, iyi bir antrenör eğitimi ve sporculara sağlıklı beslenmelerine ilişkin uzman ve yayın desteğinde bulunulmalıdır.

\section{KAYNAKLAR}

1. Açıkada, C., Ergen E., Bilim ve Spor, Büro Tek Ofset Matbaacılık, Ankara , s:5, 1990.

2. Başer , E.,Uygulamalı Spor Psikolojisi , MEGSB , Beden Terbiyesi Genel Müdürlüğü , Yayın No:31, Ankara , s:28, 1986

3. Bucher, A. Charles., Wuest . A. Deborah ., Foundations of Physical Education and Sport, Tenth Edition , Times Mirror College Published St Louise Toronto, Santo Carlo, pp:344-345, 1987.

4. Anonim, Gençlik ve Spor Genel Müdürlüğü Araştırma Planlama ve Koordinasyon Dairesi Başkanlığı, Sporda 10 Yıl, Gökçe Ofset Matbaacılık, Ankara, 1994.

5. Çol , Z, Basın ve Yayın Kuruluşlarının Alt Yapıya Katkısı , Ankara Üniversitesi Beden Eğitimi ve Spor Yüksekokulu ve Gençlik ve Spor Genel Müdürlüğü'ün 16 Aralık 1996 tarihinde ortaklaşa düzenledikleri Sporda Altyapı Sorunları konulu sempozyumda sunulan bildiri , Ankara, 1996

6. Talay, H., Türkiye Amatör Spor Kulüpleri Konfederasyonu ve Spor Alt Yapısı Çalışmaları , Ankara Üniversitesi Beden Eğitimi ve Spor Yüksekokulu ve Gençlik ve Spor Genel Müdürlügü̈'nün 16 Aralık 1996 tarihinde ortaklaşa düzenledikleri Sporda Altyapı Sorunları konulu sunulan bildiri , Ankara, 1996.

7. Quidet, C. , Wiemer Research and Its Valne, Report: Sport and TV Seminar, Oslo-Margedal, Hovden, September , pp:19-23, 1977.

8. Karaküçük S., Yenel F., Yaman M., Sporun Topluma Yaygınlaştırıması Bakımından Televizyon Spor Programlarının Etkinliği, G.Ü. Beden Eğitimi ve Spor Yüksekokulu - Beden Eğitimi ve Spor Bilimleri Dergisi , Cilt:1 Sayı:3, s:54, Ankara , Temmuz 1996. 